\title{
Consideration for declaring a Mineral Reserve for TSF mining projects
}

\author{
S.M. Rupprecht
}

Affiliation:

1 University of Johannesburg, Johannesburg, South Africa.

Correspondence to:

S.M. Rupprecht

Email:

rupprechts@gmail.com

Dates:

Received: 9 Jun. 2020

Revised: 8 Aug. 2020

Accepted: 30 Aug. 2020

Published: September 2020

How to cite:

Rupprecht, S.M.

Consideration for declaring a

Mineral Reserve for TSF mining projects.

The Southern African Institute of Mining and Metallurgy

DOI ID:

http://dx.doi.org/10.17159/2411-

9717/1246/2020

ORCiD ID:

S.M. Rupprecht

https://orchid.org/0000-0003-

2462-2819

This paper will be presented at the SAMCODES Conference 2021, 26-27 October 2021,

Mandela Mining Precinct,

Auckland Park, Johannesburg, South Africa.

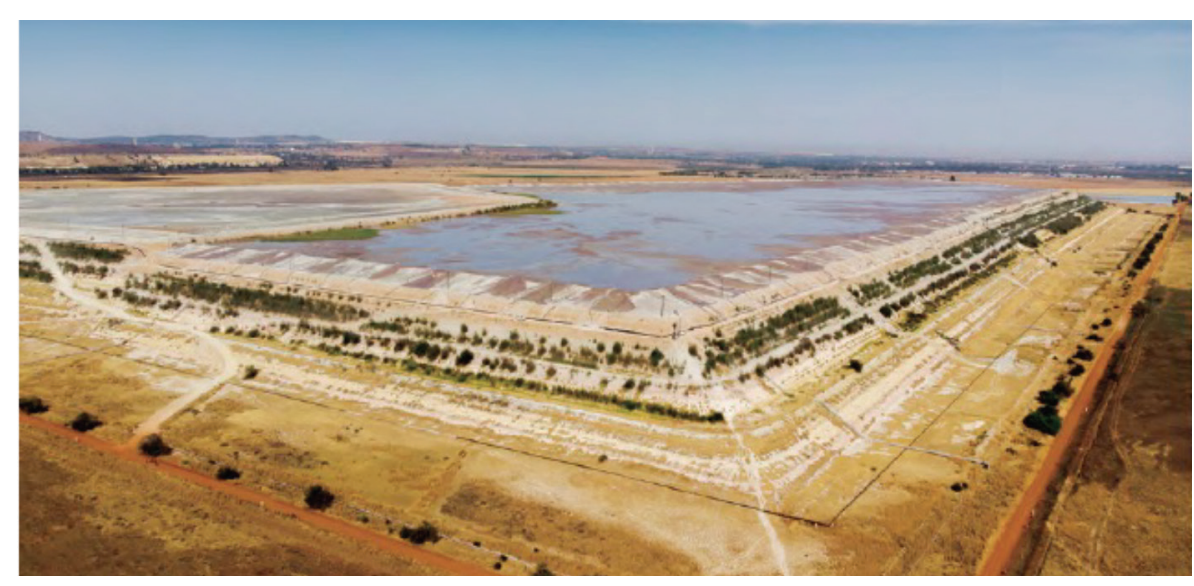

Figure 1-Typical tailings storage facility (TSF) (DRDGold IAR, 2017)

\section{Synopsis}

The mining of old tailings storage facilities (TSFs) or dams/dumps has become a common operation in South Africa. This practice has several interesting aspects that are different to normal surface mining operations. When considering the estimation of Mineral Reserves, the Competent Person must take into account the conditions of mining historical TSFs that are often situated in close proximity to communities. This paper discusses the Modifying Factors required to convert a Mineral Resource to a Mineral Reserve, such as mining sequence, dilution, mining losses, and environmental, social/community, and government factors. The paper also investigates the role that Inferred Mineral Resources may play in the life-of-mine plans for tailings dam projects.

\section{Keywords}

TSF, tailings, hydraulic mining, Mineral Reserve estimation.

\section{Introduction}

The mining of old tailings storage facilities (TSFs) or tailings dams (Figure 1) has several unusual aspects compared to the mining of most mineral deposits. The reason for this is that TSFs are not geological features but are man-made deposits similar to an alluvial deposit. However, the grade and distribution of the mineralization in the deposited tailings is generally a function of the historical metallurgical plant's design and processing efficiency, and no metallurgical plant is $100 \%$ efficient. Critical to the successful exploitation of a tailings dam is the efficiency of the modern metallurgical process to recover the mineralized material contained in the tailings, noting that modern processes are more efficient than most older processes.

\section{Background to hydraulic mining}

The use of water plus energy to mine unconsolidated material has a long history. The ancient Romans introduced the notion of large-scale mining with a technique known as hydraulic mining. This method, developed in $25 \mathrm{AD}$, required large tanks of water and aqueducts to supply the water to the tanks. 


\section{Consideration for declaring a Mineral Reserve for TSF mining projects}
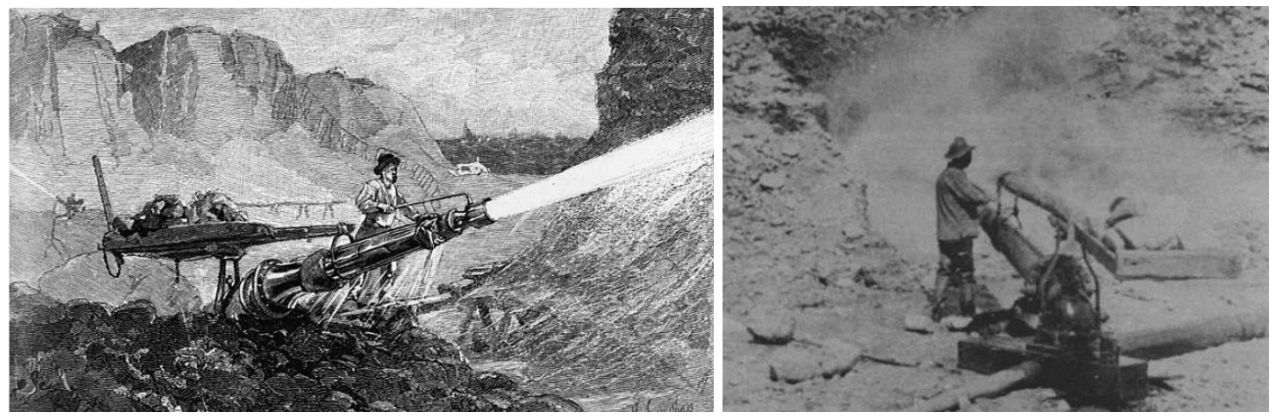

Figure 2-An example of hydraulic mining in the California gold mining operation (Anon., 2016)

When the water was released from the tanks, huge volumes of water washed away or broke the rocks, exposing the bedrock and any gold material (Anon., 2016). The best-known use of hydraulic mining is in the California Gold Rush, which was documented and provides physical evidence of the widespread and sophisticated use of hydraulic mining in the mid-19th century (Figure 2). Thousands of kilometres of ditches and flumes were constructed to gravitate water from high in the mountains at sufficient pressure to flush the alluvial gravel beds into sluices. It is reported that an 8-inch $(200 \mathrm{~mm})$ monitor could deliver $185000 \mathrm{ft}^{3}\left(5240 \mathrm{~m}^{3}\right)$ of water with a velocity of $150 \mathrm{ft}$ per second (45.7 m/s) (Anon., 2016).

In recent years, hydraulic mining (Figure 3 ) has been used for the extraction of unconsolidated mineralized materials, alluvial deposits, freshly blasted ores, and the recovery (or remining) of dewatered tailings dams/storage facilities. Hydraulic mining can be loosely defined as the excavation of material from its in-situ state using water at high pressure. A stream of water is directed at the tailings with the purpose of mechanically breaking and/or softening the mineralized material so that it can be carried away by the water flow. The application or effectiveness of the method is a function of a variety of factors, ranging from the size, velocity, and pressure of the water stream to the location, hardness, particle size, and moisture content of the material being mined.

The effectiveness of hydraulic mining is a result of decades of successful reclamation and re-deposition operations. The method entails high-pressure water delivered to the reclamation sites by a network of pipelines to the reclamation faces.

\section{Modifying Factors}

Establishing Mineral Reserves is important for mines and projects as the ability to declare a Mineral Reserve demonstrates the financial viability of a mine or project (Rupprecht, 2016a). The conversion of Mineral Resources to Mineral Reserves requires Modifying Factors to be considered. Notably, TSFs are man-made facilities used to store the residue material from metallurgical processing plants. If the contained mineralized material is found to have Reasonable Prospects for Eventual Economic Extraction (RPEEE) based on improved metallurgical recovery techniques, original sulphide material partially oxidized making recovery possible, and/or significant increases in metal prices, a Mineral Resource can be declared. Typically, TSFs are low-grade deposits that require a high volume/low-cost operation to enable viable mining. In some instances, government authorities have requested mining companies to remove old TSFs in areas deemed high risk to the general population as a means to eliminate the dangers of dam failure, dust pollution, and other socially unacceptable factors.

\section{Mining method}

Typically, the pressure used for hydraulic mining is $3000 \mathrm{kPa}$ to $4000 \mathrm{kPa}$ (30-40 bar) at the pump station, reducing to about $2400 \mathrm{kPa}$ bar at the gun or hydraulic monitor (monitor gun). It should be noted that for well-graded, non-cohesive (sandy), coarser tailings that are often found along the tailings dam wall, the hydraulic water pressure should not be less than $3200 \mathrm{kPa}$ at the monitor gun (Fraser Alexander, 2002).

Depending on production rates required, multiple monitor guns will be in operation and the high-pressure water delivered to the reclamation area will generally be distributed by 250 $\mathrm{mm}$ diameter pipes with water reaching the monitor guns at a pressure of approximately 3000-4000 $\mathrm{kPa}$. The monitor guns concentrate and direct the high-pressure water to the reclamation

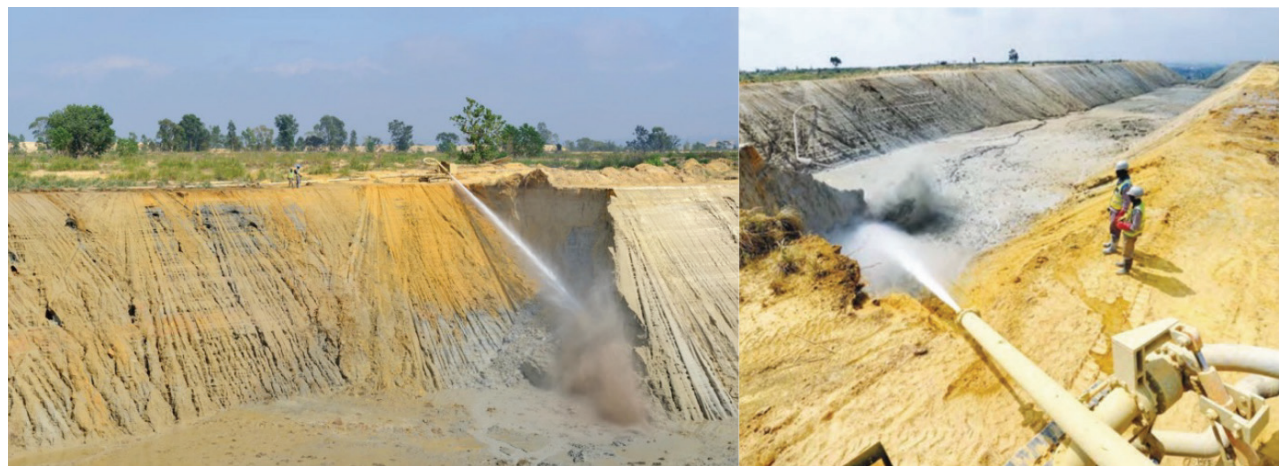

Figure 3-Examples of hydraulic mining of a TSF/tailings dam (DRDGold IAR, 2017) 


\section{Consideration for declaring a Mineral Reserve for TSF mining projects}

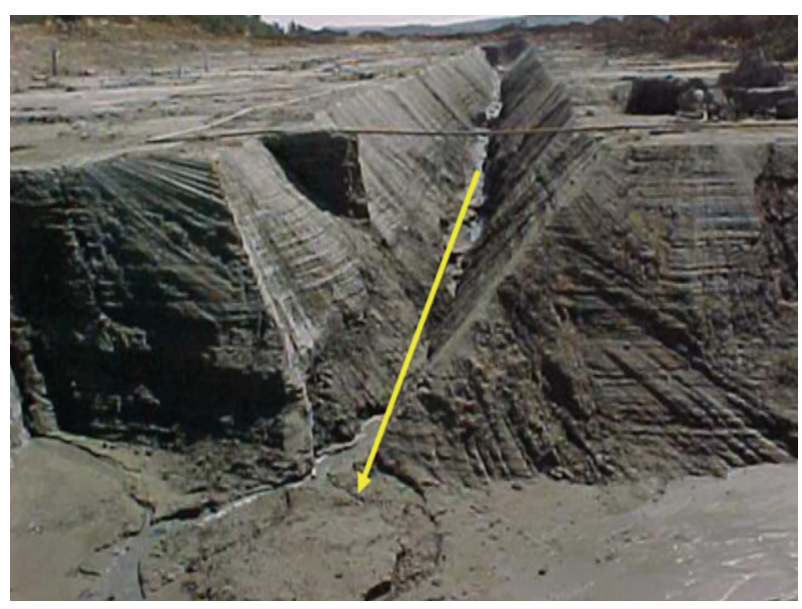

Figure 4-Gully used to transport slurry (Fraser Alexander, 2012)

focus area to pulp the tailings into a slurry and maintain slurry densities between $1.40 \mathrm{t} / \mathrm{m}^{3}$ and $1.46 \mathrm{t} / \mathrm{m}^{3}$. Each monitor (150 $\mathrm{mm}$ ) can excavate approximately $4000 \mathrm{t}$ of tailings per day.

The slurried tailings material is broken up and mixed with water by the monitor guns, which enables the slurry to flow under gravity along channels or gullies (Figure 4). Finger screens are used in the gullies to remove coarse $(+50 \mathrm{~mm})$ material. The slurry or run-of-mine (RoM) material gravitates to the pond pumps or sump pumps. These pumps then pump the slurry over vibrating screens, fitted with 2-3 $\mathrm{mm}$ aperture polyurethane screen panels, to remove any fine debris that may impact the pumping operations (Figure 5). The slurry is then pumped to the slurry tank and from there to the processing plant. Hydraulic mining is not labour-intensive and can produce

$100000 \mathrm{t} /$ month with only a few workers.

Slurried tailings tend to flow at a natural beaching angle that is generally self-correcting. If the slope is too steep, the flow velocities increase in the channels, causing erosion until the equilibrium slope is attained. The tailings material consists of fine tailings slimes with a typical particle size of $80 \%$ passing 150 $\mu \mathrm{m}$. Relatively flat flow channels are developed, with gradients in the order of 1:100 or flatter (Figure 4).

The mining of old or defunct TSFs differs from other mining

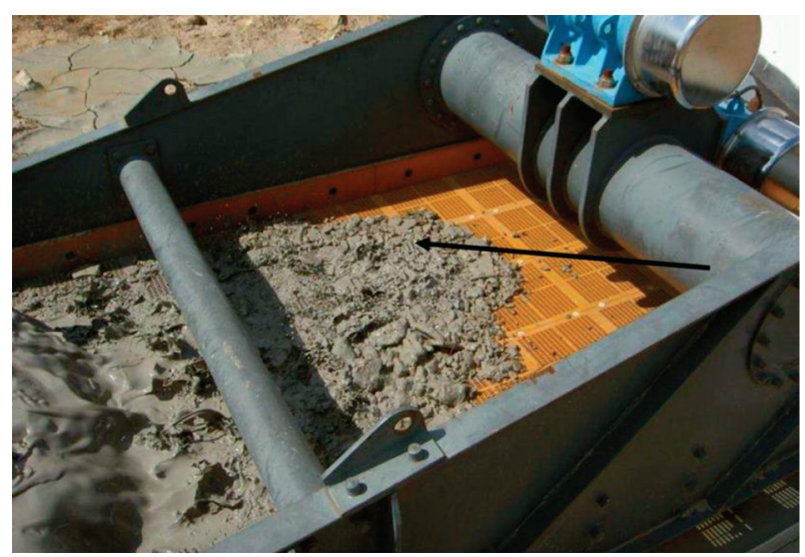

Figure 5-Example of vibrating screen to remove debris from the slurry (Fraser Alexander, 2012) operations in that once the decision is made to mine the TSF, the mining needs to be completed in totality. As the TSFs are frequently in or close to populated areas, their removal can free up valuable land and eliminate an environmental nuisance, especially dust.

The final stage of the mining of a TSF is floor cleaning, where the hydraulic gun is on the natural ground level, washing the shallow depth of tailings away from the gun. Floor cleaning is conducted until too much stone enters the ROM feed (blocks the screens too often). The final ore is collected during final clean-up of the tailings dam floor at the end of the life of the operation, after which the tailings dam is rehabilitated.

\section{Cut-off grades}

A break-even cut-off grade should be used based on establishing the average grade of the tailings dam. Although historical TSFs are generally auger drilled and sampled, allowing the construction of a 3D block model, it is common practice to apply an average grade (pay limit). The reason for this is that TSFs are re-mined and processed in their entirety, and no selective mining is possible. Therefore, the grade of the entire tailings dam must be used to determine its economic viability. Another reason that the average mining grade is used in the cut-off estimation is that mining is conducted from several faces, making reconciliation more difficult. Grade reconciliation is further complicated when ore is sourced from a number of TSFs, thus making it difficult to accurately reconcile grades on a monthly basis. Experience based on the DRDGOLD Limited operations indicates a very close correlation between planned and actual grades on an annual basis (Labuschagne, 2019).

\section{Mining loss and dilution}

As the entire tailings dam is mined, inclusive of the rehabilitating of the original footprint, it is common practice in South Africa not to apply a mining loss or mining dilution. Accordingly, no dilution or mining loss is applied in the process of converting Mineral Resources to Mineral Reserves. Furthermore, due to the size of TSFs the potential dilution and mining losses are small and would not have a material impact on the Mineral Resource to Mineral Reserve conversion.

\section{Geotechnical}

TSFs in South Africa have been successfully exploited since 1977, and the geotechnical characteristics are well understood from practical experience. A safe bench height is dependent upon the material strength, which is influenced by the phreatic surface within the dump (The term 'phreatic surface' indicates the location where the pore water pressure is under atmospheric conditions, i.e. the pressure head is zero. The phreatic zone, below the phreatic surface where rock and soil is saturated with water, is the counterpart of the vadose zone, or unsaturated zone, above). As no open-pit mining is taking place, the mine design does not account for slope angle but rather the natural angle of repose from hydraulic mining. As most TSFs have been dormant for many years the phreatic surface is below the surface of the dry tailings material and therefore the risk of encountering saturated zones or phreatic surfaces that may cause slope failure is low. To ensure the competency of the wall, an angle of 45 to 35 degrees (Figure 6) is typically used. This angle is based on years of experience of working with dry tailings. 


\section{Consideration for declaring a Mineral Reserve for TSF mining projects}

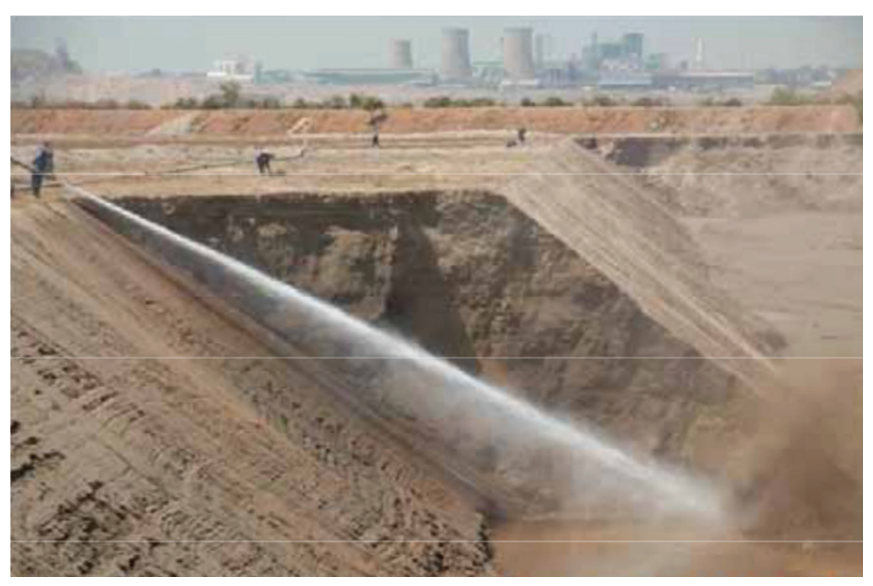

Figure 6-Mining at a $45^{\circ}$ angle (Garling and Prentice, 2010)

\section{Metallurgical processing and recovery}

An understanding of the recovery of any metallurgical process is essential. In the case of mining mineralized TSFs, the recovery is low, typically in the order of a $40 \%$ to $50 \%$, noting that not all tailings respond favourably to flotation. Like all mineral projects, metallurgical test work should be conducted. In the case of mining tailings dams, the project should include metallurgical test work during the evaluation drilling programme.

\section{Project infrastructure}

Unlike most surface mining operations, tailings operations are dependent upon the ability to transfer mineralized material from the dams to the beneficiation plant as a slurry. Key points are the availability of servitudes and surface rights for slurry and water pipelines, including road crossings. The availability of power and water is critical to establishing the viability of the project. Both these items are significant when considering operating costs and recovery.

\section{Capital and operating costs}

Capital expenditure for general infrastructure must be considered in the process of converting a Mineral Resource to a Mineral Reserve. The availability of a suitable processing plant is critical, and this must be adequately designed and costed. For existing operations planning to re-treat tailings material, this may not be a critical issue. However, for a new entrant, the capital cost of a dedicated beneficiation plant could be very high, and in some cases the capital requirements may make the project uneconomic. As most companies make use of specialized contractors to conduct the mining operations, the mining-related infrastructure requirements are often included in the contractor's rates.

In terms of operating costs, sand dams involve a higher cost than slimes, since sand can wear the pipelines quicker than slimes. In some cases, sand can be added to slimes to improve the flow. In addition to the operational issues, a further reason for the increase in the operating cost is that sand must be milled to approximately $80 \%$ less than $75 \mu \mathrm{m}$ while the slime, although coarser, can be treated in the carbon-in-leach tanks directly. Total mine operating costs range from R50 to R200 per ton (2019) with $\mathrm{R} 85$ per ton being a reasonable average. Operating costs are inclusive of the following:

$>$ Labour
$>$ Consumables
$>$ Electricity
$>$ Water
$>$ Cohabilitation
$>$ Other.

\section{Governmental, legal, and permitting}

The Competent Person (CP) must ensure that all legal aspects, mining rights, surface agreements, servitudes, and permits are in place to justify the declaration of a Mineral Reserve. The CP must also ensure that there are currently no legal actions/impediments that would prevent operations on any of the current mineral rights.

\section{Social, environmental, or community impact}

One of the biggest concerns by communities is the nuisance created by dust from the TSFs, which can impact on those living within the mining areas of influence. The re-mining of TSFs is unique in that, unlike other mining projects, the exploitation (rehabilitation) of a historical TSF can improve the local environment, as depicted in Figure 7. Many of the TSFs that are subject to re-mining are historical and due to their age, many are surrounded by towns and communities. For example, Johannesburg, Benoni, and Boksburg have expanded beyond their original city limits with communities now living adjacent to these old TSFs.

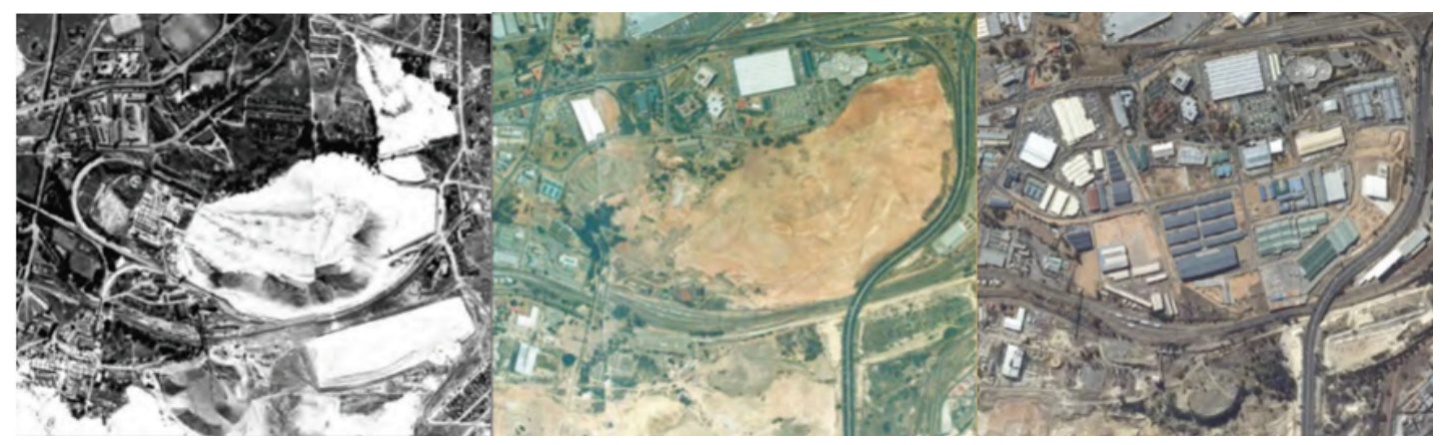

Figure 7-Sequence of rehabilitation through mining (left to right, tailings dam, re-mining site, industrial site) (DRDGold IAR, 2017) 


\section{Consideration for declaring a Mineral Reserve for TSF mining projects}

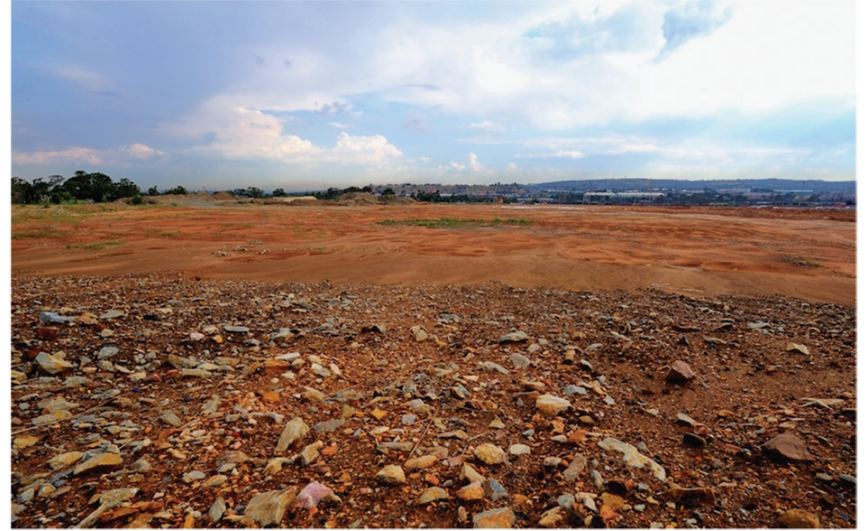

Figure 8 - Example of a rehabilitated dam site

Importantly, the mining of the TSFs opens up large tracts of land which, once properly rehabilitated, can be used for other purposes such as industrial sites or local housing. Furthermore, as TSFs are completely mined it is important that the tailings dam footprint is rehabilitated, closure is certified, and the site released for land redevelopment purposes as soon as practically possible. The final clean-up is a time-consuming and costly activity, and because of this, many sites where mining has been completed are not fully rehabilitated. Travelling around the greater Johannesburg area, one can observe numerous sites requiring final rehabilitation and closure approval.

Figure 8 provides an example of a tailings dam site that has been rehabilitated.

Environmental management is a crucial aspect during the project planning phase of new mining sites. Key impacts from the mining of TSFs include the following.

- Air quality can be affected in that mining activities can increase dust levels in the vicinity of the operations.

- Surface water can be affected by slime spillage from pipelines and pump areas, which could impact on local water quality.

> Mining of some TSFs may promote acid mine drainage as minerals in the tailings are oxidized.

> Noise due to mining operations and associated activities may be a nuisance to local communities.
As part of the Environmental Impact Assessment, operations are required to identify and mitigate anticipated impacts. During the Mineral Resource to Mineral Reserve conversion process, the $\mathrm{CP}$ must ensure that environmental aspects are well managed and that the company has addressed all legal and environmental compliance requirements. The $\mathrm{CP}$ must identify all sensitive areas or environmental factors that could materially affect the tailings project and ensure that these have been addressed or efficiently mitigated. Finally, the CP must ensure all necessary permits are in place or that there is a reasonable basis to believe that all permits required will be obtained.

\section{Market studies and economic considerations}

As with any mineral project for which a Mineral Reserve is to be declared, the market conditions must be understood, especially the cyclical nature of commodity prices as mining of TSFs can be a lengthy (medium-to-long-term) process. Mining engineers also need to account for the fact that TSFs are marginal deposits that require sufficient Mineral Resources mined at an appropriate production rate. Most require production of the order of 300 $000 \mathrm{t} / \mathrm{month}$ to establish sufficient economies of scale and lower operating costs enough to make mining economically viable. For example, many gold tailings dumps found around Johannesburg have typical grades of $0.3 \mathrm{~g} / \mathrm{t}$ or lower. These dumps are sensitive to revenue drivers such as grade, recovery, and the gold price, and a material decrease in any of these revenue drivers can have a direct negative impact on the viability of the operations. Therefore, it is crucial that the projected commodity price used in the Mineral Reserve estimation be sufficiently conservative to support mining operations and account for the cyclical changes in commodity prices for the full duration of the project.

Once a tailings operation commences it is often very difficult to halt operations during periods of low commodity prices. This is due to the fact that mining operations disturb previous environmental safeguards such as grass cover, water management, etc. The premature stoppage of a tailings project will cause the TSF to be exposed to the natural elements, which may increase the risk of dust, acid mine drainage, and other hazards. Some partially mined dumps around the Johannesburg can attest to this, notably the partially mined sand dumps in Krugersdorp.

\section{Risk assessment}

Risk assessment is a vital factor to be considered when

\begin{tabular}{|l|l|}
\hline Table I \\
Key inputs & Grain size (Steenkamp, 2016) \\
\hline Geochemical and physical characteristics (Steenkamp,2016) & Level of oxidation (Steenkamp,2016) \\
\hline Homogeneity (Steenkamp,2016) & Grade or percentage of metal \\
\hline Penalty elements (Steenkamp,2016) & Specific gravity \\
\hline Size of Mineral Resource & Process recovery \\
\hline Metal price & Infrastructure, surface rights, and servitudes \\
\hline Access to reliable power and water supplies & Social license to operate \\
\hline Operational costs - including the cost of electricity and cost and supply of water & Environmental compliance \\
\hline Governmental compliance & Regulatory compliance \\
\hline The proximity of communities and informal settlements & \\
\hline
\end{tabular}




\section{Consideration for declaring a Mineral Reserve for TSF mining projects}

converting Mineral Resources to Mineral Reserves, but its importance is often underestimated by mining companies. The risk assessment should include all technical specialists involved in the mining operations to identify aspects that could impact not only on the project achieving its business plan, but more importantly those aspects that may affect the estimation of the Mineral Resource and the declaration of a Mineral Reserve.

The mining of TSFs does embody risks often not usually associated with standard surface mining. TSFs are high-tonnage low-grade deposits that are revenue-sensitive (metal price, recovery, grade). Technical aspects that that may influence the declaration of Mineral Reserves are listed in Table I.

\section{Inferred Mineral Resource}

Owing to the nature of old TSFs, it is often not feasible to conduct exploration on the full footprint of the tailings dam due to external issues, such as municipal waste, dense vegetation, or water ponding. As previously discussed, the very nature of mining TSFs requires the mining of the full deposit, regardless of the classification. Leaving material or Mineral Resources that are not upgradeable to Mineral Reserves would only negate the positive attributes of the mining process. This would in fact create far worse environmental conditions as the remaining TSF would be affected by the natural environment (rain and wind) and adversely impact the local environment. Although it is best practice to limit the amount of Inferred Resources in a mine design (Rupprecht, 2016b), it may be necessary to include Inferred Mineral Resource in the mine plan. Under the SAMREC Code 'It is accepted that mine design and planning may include a proportion of Inferred Mineral Resources, albeit under certain reporting conditions'.

However, it is interesting to note that in many international reporting codes, the use of Inferred Mineral Resources in the lifeof-mine plans is prohibited, and is allowed only in the reporting in Scoping Studies (Clause 38 - JORC Code, 2012) or Preliminary Economic Assessments (NI 43-101). For example, the JORC Code (2012) provides the following guidance:

'Confidence in the estimate of Inferred Mineral Resources is not sufficient to allow the results of the application of technical and economic parameters to be used for detailed planning in PreFeasibility or Feasibility Studies.'

In the author's opinion, the inclusion of Inferred Mineral Resources is a perfect example of where the CP should be allowed to use his/her judgement to include Inferred Mineral Resources into the mine plan, as:

- The tailings dam consists of material produced from metallurgical plants known to yield less-than-perfect recovery. Therefore, there is a high probability of continuous mineralization and homogenous grade.

> In general, the mining method does not support selective mining.

> Once mining commences the tailings dam should be removed in its entirety.

Therefore, it would not be unreasonable to consider the inclusion of Inferred Mineral Resources in a TSF re-mining project. However, one should take into account and comment on the risk associated with the inclusion of Inferred Mineral Resource in the mine plan.

\section{Conclusion}

The mining of TSFs, and therefore the declaration of a Mineral Reserve, is unlike most mineral projects in that the deposit is man-made and its characteristics depend upon the deposition characteristics of original TSF design and operation. Furthermore, unlike natural deposits, TSFs are above ground, often in close proximity to housing, communities, and other businesses, and therefore the removal of the TSF is often viewed as removing an environmental nuisance, i.e. dust, source of acid mine drainage, as well as opening up ground for urban development. Once mining commences, the grass cover and other environmental protections are disturbed, and the mining project must be completed. Therefore, understanding the sensitivity of the pay limit of the dumps in the life of mine and the long-term metal prices is essential, as one does not want to leave a partially mined tailings dam.

Owing to the environmental issues surrounding tailing projects, once mining commences the project should be completed so that the area can be returned to the landowner in as close to the original condition as possible.

\section{References}

Anon. 2016. Hydraulic gold mining and the history of the West https:// raregoldnuggets.com/?p=2630 [accessed: 23 April 2020].

DRDGoLD Limited. 2017. Integrated Annual Report (IAR).

Fraser Alexander. 2002. Re-mining operational standards. Internal training document. Johannesburg.

Garling, R. and Prentice, D. 2010. Hydraulic Mining, Proceedings of the Cobar Mining Seminar. 8 August 2010. Hydraulic Mining Solutions.

JORC. 2012. Australasian Joint Ore Reserves Committee. Australasian Code for Reporting of Exploration Results, Mineral Resources and Ore Reserves. The Joint Ore Reserves Committee of the Australasian Institute of Mining and Metallurgy, Australian Institute of Geoscientists, and Minerals Council of Australia. http://www.jorc.org/docs/JORC_code_2012.pdf

Labuschagne, V. 2020. Personal Communication, 23 April 2020. DRDGOLD Limited, Johannesburg.

Rupprecht, S.M. 2016a. The application of modifying factors. Proceedings of the SAMREC/SAMVAL Companion Volume Conference, Emperors Palace, 17-18 May 2016. Southern African Institute of Mining and Metallurgy. Johannesburg. pp. $187-194$.

RuPPRECHT, S.M. 2016b. Good reporting practices. Proceedings of the SAMREC/ SAMVAL Companion Volume Conference, Emperors Palace, 17-18 May 2016. Southern African Institute of Mining and Metallurgy, Johannesburg. pp. 1-12

SAMREC. 2016. South African Mineral Resource Committee. The South African Code for the Reporting of Exploration Results, Mineral Resources and Mineral Reserves (the SAMREC Code. 2016 Edition. http://www.samcode.co.za/codes/ category/8-reporting-codes?download=120:samrec

SteEnKamp, N.C. 2016. Considerations for reporting of tailings. Proceedings of the SAMREC/SAMVAL Companion Volume Conference, Emperors Palace, 17-18 May 2016. Southern Africa Institute of Mining and Metallurgy. Johannesburg. pp. 163-172 